\title{
Rechtliche Lage
}

\section{Corona-Impfpflicht für Praxispersonal?}

\author{
Die Corona-Impfkampagne hat begonnen. Könnte nun eine \\ Impfpflicht für Mitarbeiter in Praxen und Kliniken kommen? \\ Durchaus denkbar, sagt Arztrechtler Professor Alexander Ehlers.
}

$\mathrm{K}$ aum sind die ersten Menschen gegen Corona geimpft, beginnen die Debatten darüber, welche Vorteile Geimpfte im Vergleich zu Ungeimpften genießen könnten. Es könnten aber auch Pflichten auf manche Berufsgruppen zukommen, etwa auf Ärzte oder Medizinische Fachangestellte (MFA). Die juristische Handhabe dafür wäre vorhanden, glaubt der Arzt und Fachanwalt für Medizinrecht Prof. Alexander Ehlers. Die Bundesregierung habe durchaus Eingriffsmöglichkeiten, eine Impfung gegen SARS-CoV-2 zur Voraussetzung für die Arbeit mit Patienten zu machen, so Ehlers.

\section{Beispiel: Masernschutzgesetz}

Ein Beispiel für ein solches Vorgehen gebe das Masernschutzgesetz, das seit April 2020 eine Masern-Impfpflicht für Beschäftigte im Gesundheitswesen vorsieht. Eine Teilimpfpflicht für Ärzte, MFA und Krankenschwestern sei verhältnismäßig, um Patienten zu schützen. Es gebe allerdings noch keine abschließende Rechtsprechung, schränkte Ehlers ein.

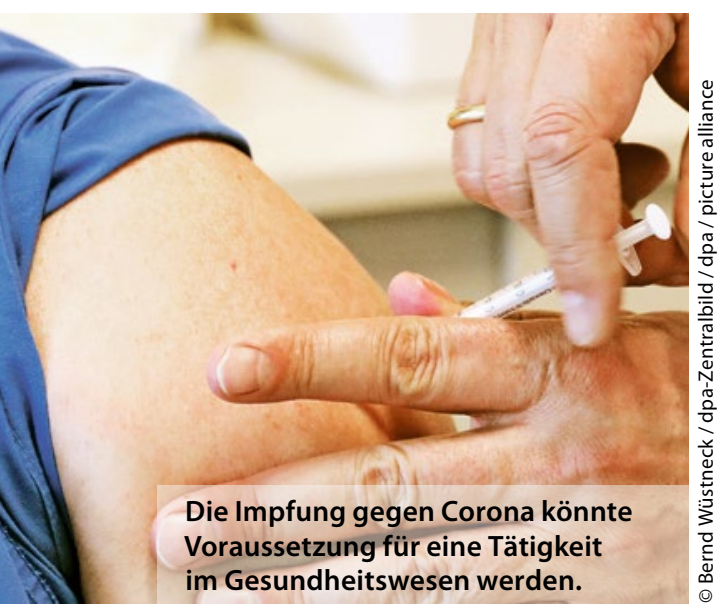

Der Rechtsanwalt sieht selbst bei einer allgemeinen Impfpflicht die Eingriffsmöglichkeiten der Bundesregierung juristisch relativ klar abgesichert. „Die Ermächtigungsgrundlage für eine Impfpflicht ist im Infektionsschutzgesetz aktuell geschaffen worden", so der Jurist. Eine Zwangsimpfung für vulnerable Gruppen sei im Fall einer Pandemie durch eine Rechtsverordnung des Bundesgesundheitsministeriums (BMG) möglich - mit Zustimmung des Bundesrates. Und wenn sich das BMG nicht zu einer solchen Verordnung durchringen könne, seien auch die Landesregierungen dazu ermächtigt.

\section{Kontrollinstanz}

\section{Bundesverfassungsgericht}

Die letzte Kontrolle, ob solch ein Eingriff in die körperliche Unversehrtheit - und das sei eine Impfung immer - rechtskonform ist, liege dann beim Bundesverfassungsgericht in Karlsruhe, erklärte Ehlers. $\mathrm{Zu}$ einer allgemeinen Impfpflicht hätten die Verfassungsrichter aus Anlass der Pockenschutzimpfungen bereits 1959 entschieden, dass eine Impfpflicht, die darauf ziele, die körperliche Unversehrtheit zu erhalten, beispielsweise durch Erlangung einer Herdenimmunität, verhältnismäßig ist, erinnerte der Medizinrechtler.

Eine andere Frage sei, ob durch eine Impfpflicht nicht der Widerstand gegen eine Impfung verstärkt werden könnte. "Es gibt noch andere Instrumente als eine Impfpflicht, die zum Ziel führen könnten." Auch Ehlers hofft, dass die Einsicht bei der Mehrheit der Bundesbürger überwiegt, dass eine Impfung im Vergleich zu einer COVID-19-Erkrankung das kleinere Übel wäre - und dass somit bereits durch freiwillige Impfungen eine Herdenimmunität erreicht werden könnte.

Impfpflicht durch die Hintertür?

Eine klare Meinung hat der Rechtsanwalt zu der in den vergangenen Tagen heftig diskutierten Frage, ob Geimpfte im Vergleich zu Ungeimpften Sonderrechte genießen dürfen: Könnten Anbieter von Pflegedienstleistungen beispielsweise Patienten bevorzugen, die bereits eine Impfung gegen COVID-19 vorweisen? Dürfte eine Fluggesellschaft Ungeimpfte als Passagiere zurückweisen?

Gesundheitsminister Spahn, Innenminister Seehofer und das Justizministerium machten klar: Keine „Impfpflicht durch die Hintertür" - zumindest vorläufig. Laut der Ministerin für Justiz und Verbraucherschutz Christine Lambrecht „verbieten sich gegenwärtig Privilegien für Geimpfte“. In der Regierungskoalition gibt es derzeit sogar Diskussionen darüber, ob derartige Sonderrechte gesetzlich untersagt werden könnten.

Ehlers ist skeptisch: „Wenn geimpfte Personen für sich in Anspruch nehmen, nach neun Uhr abends, was derzeit in Bayern verboten ist, wieder auf der Straße unterwegs zu sein, dann ist das kein Sonderrecht, sondern das wäre die Rückführung in die verfassungsrechtlich garantierte Normalität.“

Wenn eine geimpfte Person keine Gefahr mehr für die Gesundheit anderer darstelle, dann wäre ein Eingriff in seine Freiheitsrechte nach Ansicht des Juristen „nicht mehr verhältnismäßig“. Genau diese Frage sei bislang medizinisch noch nicht geklärt: „Wir wissen, dass der Geimpfte durch die Impfung geschützt ist, wir wissen aber noch nicht, ob er das Virus auch nicht mehr weitertragen kann." Der Hersteller BioNTech erwartet bis Ende Februar Daten dazu, ob der Impfstoff auch andere Personen vor einer Ansteckung durch den Geimpften schützt.

Hauke Gerlof 